\title{
Älykäs kunta, missä olet?
}

\section{Sami Tantarimäki}

Puhumme digiyhteiskunnasta. Älykäs kaupunki (smart city) on jo käyttöön vakiintunut käsite, maakunnat (smart region) älykään erikoistumisen (smart specialisation) asialla ja maaseutu (smart countryside) entistä enemmän esillä Euroopan komission lanseeraaman smart village -aloitteen myötä. Miksi kunnankin (smart municipality) pitäisi olla mukana?

\section{Älykkyyden aluehierakia}

Mitä useammalla aluehierarkian tasolla älykkään aluekehittämisen konsepteja ilmenee, sitä mielenkiintoisemmaksi asia muuttuu aluekehittämisen kannalta. Älykkään aluekehittämisen tavoitteet ja tarpeet ovat pitkälti samoja, ja monet ratkaisut toteutettavissa hierarkian tasosta riippumatta. Paikka- ja tietoperustaisesti halutaan olla digiyhteiskunnassa kiinni ja pysyä sen mukana. Teemojen ja tarpeiden kohdatessa läpileikkaavuuden tavoitteluun luulisi olevan jopa yhteisiä intressejä, kun ajatellaan aluetta ekosysteeminä (mm. Sutriadi, 2018; Tantarimäki, 2020a). Läpileikkaavuutta voisi toteuttaa resursointia tukevassa ohjelmatyössä, digistrategioissa ja alue- ja innovaatiopolitiikoissa.

Maakuntatasolta tarkasteltuna alue-ekosysteemin voi nähdä toisiinsa kytköksissä olevana kuntien kokonaisuutena, kaupunkien ja maaseutujen kokonaisuutena, kuntaterveysyhtymien kokonaisuutena, yhteisöjen kokonaisuutena tai vaikka älykkäiden kaupunkien, kylien ja maaseutujen kokonaisuutena (Yashar, 2016). Jälkimmäinen on pitkälti sitä, mitä Uusimaa brändillään antaa ymmärtää: "Smart city + smart coutryside = smart region" (Uusimaa, 2020). Oletusarvoisesti kaikki kunnat ovat osa tätä kehittämisen kokonaisuutta ja tavoitteen toteuttamista.

Vaikka kehittämisen konsepteja eri aluetasoilta tunnistaakin, isossa kuvassa "smart-näkymä" on vielä varsin pistemäinen ja alueellisessa älykkyydessä löytyy selkeitä aukkoja paikattavaksi. Esimerkiksi älykäs kaupunki -konsepti vaikuttaa 
suurkaupunkien kerholta, jonne pienillä ja keskikokoisilla kaupungeilla ei ole asiaa. Näin yksioikoinen arki ei sentään ollut, kun todellisuutta tarkemmin tarkasteli (Tantarimäki, 2020a). Maaseudun kantilta katsottuna älykäs kylä on "in”, mutta sekin vaikuttaa pieneen pisteeseen tuijottamiselta. Tämäkään ei ole totuus, sillä tavoitteena älykkäässä kylässäkin on tunnistaa paikallinen innovaatiopotentiaali ja tasoittaa alueellisia eroja samoin kuin kehittää keskusten ketjua kylistä kuntien kautta kaupunkeihin (ENRD, 2018; Woien \& Teräs, 2019). Kuntien rooli älykkään kehittämisen ketjussa on kuitenkin kysymysmerkki.

\section{Muutosjoustavuuden momenttiavain}

"Smart specialisation as a tool for regional resilience". Tähän Nordregio Forumin keynote-puheen otsikkoon (Berkowitz, 2019) kiteytyy hyvin se, mistä pohjimmiltaan on puhe. Puheenvuoron otsikossa esitetty kysymys kytkeytyy yhteiskunnallisessa keskustelussa siihen, mitä tarkoittaa kuntien älykäs muutokseen sopeutuminen (vrt. Ahonen \& Savolainen, 2020). Mitä se tarkoittaa tilanteessa, jossa samaan aikaan kuntien eriytymiskehitys vaikuttaa voimistuvan ja alueellisia eroja pyritään tasaamaan älykkään erikoistumisen periaattein ( $\mathrm{mm}$. Ahonen \& Savolainen, 2020; Teräs, 2018)? Tai tilanteessa, jossa korona (COVID-19) kurittaa kuntataloutta entisestään ja karsimista kammetaan toistuvasti otsikkoihin samalla, kun työn murros, työn muuttuva maantiede sekä teknologia tarjoavat uusia avauksia (Tantarimäki, 202ob; Borges, 2020; Valtavaara, 2020)? Ollaan arvopohdintojen äärellä hyvinkin (vrt. valtavaara, 2020).

Mikä on kuntien valmius lähteä kehittämään älykästä muutosjoustavuutta? Löytyykö valmiutta tarkistaa suunnittelun paradigmaa vaikkapa älykkään sopeutumisen (smart shrinking) suuntaan (mm. Hollander \& Nemeth 2011, s. 253, 355; Peters ym., 2018, s. 41; Syssner, 2020; Coppola, 2019)? Kehittäminen voi toki olla myös samanaikaisesti sekä supistavaa että kasvuhakuista ainakin sen perusteella, miten yksi pikkukaupunki kysyessäni yhtälöä kuvasi:

"Palvelurakennetta on väistämättä supistettava, mikäli asukasluku jatkaa laskuaan ja syntyvien lasten määrä laskee edelleen. Kaupunkia on kuitenkin kehitettävä ja pyrittävä hakemaan kasvua uusilta toimialoilta ja uudistettava toimintaa."

Työkaluja toimimiseen kannattaa lähteä etsimään ensin omasta asenteesta ja omalta puolen aitaa, vasta sitten vihreyttä vertaillen. Vastaavan lopputulemaan tulivat kuntien älykästä kehittämistoimintaa tutkineet Kurkela ym. (2016):

"Olipa kuntaorganisaatio missä toimintaympäristössä tahansa, sitä ympäröi oma mahdollisuuksien maailma. Tärkeää on, että kunta tun- 
Myös MDI (2017) päätyy pienten ja keskisuurten kaupunkien tulevaisuuspohdintojen äärellä siihen, että "fiksu paikka löytää megatrendeistä ja niiden vastavirrasta menestyksen eväät". Ponnistetaan omista lähtökohdista eikä ahtauduta perusteetta samaan muottiin samalla logiikalla (mm. Jäntti, 2019; Katajamäki, 2019). Kaupunki, kunta tai maaseutu ei ole yksi, vaan on kaupunkeja, on kuntia ja on maaseutuja, jotka muodostavat jatkumon, verkoston ja laajemman alueekosysteemin. Siksi kysyn, missä olet älykäs kunta?

\section{Olen rivien välissä}

Kunnissa on älykästä kehittämis- ja kokeilutoimintaa, kuten esimerkiksi Kurkelan ja kumppanien (2016) selvitys osoittaa. Kuntia on mukana myös älykästä kehittämistä edistävissä (tai edistäneissä) selvityksissä, ohjelmissa ja hankkeissa, samoin kuin kasvukäytävä- ja Hinku-kuntaverkostoissa (Kuntaliitto, 202ob; Keskipohjanmaa, 2020; Suomen kasvukäytävä, 2020; Suomen ympäristökeskus, 2020).

Kaikkea ei tietenkään tarvitse nimetä "älykkääksi", tai pitää sellaisena, vaikka uutta teknologiaa ja ajattelutapaa kunnan toiminnoissa käytettäisiin tai suunnitelmissa esiintyisi. Toisin sanoen voidaan tunnistaa ratkaisuja, jotka ovat liitettävissä niin smart city -konseptiin kuin muihin älykkään aluekehittämisen konsepteihin (Lopez \& Oliveira, 2016; Kurkela ym., 2016; Tantarimäki, 2020a,b). Älykkyys ei saa olla myöskään päälle liimattua "imagoshoppailua", vaan pitää pystyä määrittelemään, miksi halutaan olla smart, mitä se vaatii ja kenelle sitä tehdään (Hollands, 2008, s. 305-310; Angelidoun, 2017, s. 89). Sitä tehdään asukkaille ja yhteisölle, kuten jo alkuperäinen smart community -ajatus osoittaa. Alunperin myös alue on määritelty joustavasti "from neighborhood to a multi-county region". Myös siksi niin älykkyyden maantiede kuin älykkyyden ajureiden aluehierarkinen läpileikkaavuus on hyvä pitää mielessä.

Selvää on, että smart municipality tai älykäs kunta ei ole yleinen käsite. Jos se mainitaankin, löytää itsensä helposti älykkäiden kaupunkien parista. Kuntia kaupungit toki ovat. Käsite kuitenkin on käytössä ja keskusteluissa myös kunta-nimikettä kantavia kuntia ajatellen (esim. Smart Innovation Norway, 2020, The Union of Municipalities of Turkey, 202o; Trimis, 2019; Väliharju, 2019), joten siitä on perusteltua puhua ja sitä on perusteltua jopa tavoitella.

\section{Älykäs kunta asiaksi}

Suomalaisen(kin) älykkään kunnan tunnistaa ja löytää, mutta se ei paistattele parrasvaloissa. Tilanne on sama pienten ja keskikokoisten kaupunkien kanssa (Tantarimäki, 2020a). Tarkempi kuntien visioiden, suunnitelmien ja hankkeiden tarkas- 
telu kuitenkin osoitti, että maamme 107 kaupungista 70 oli liitettävissä älykäs kaupunki -konseptiin. Osa tiukemmin, osa väljemmin. Vastaavalla tavalla 203 kunnan joukosta löytyisi varmasti älykkäitä kuntia - itsensä nimeämänä tai tietämättään. Tämä tarkastelu tullaan vielä tekemäänkin, jotta kokonaiskuva älykkään alueen rakentumiseen täsmentyy entisestään.

Älykkään aluekehittämisen omaksuminen ottaa aikansa. Kaupunkien osalta asiaa on harjoiteltu pisimpään, mutta kritiikittä ei ole silti selvitty: keskustelua ja tutkimusta on pitkään dominoinut one-size fits all-kerronta. Samat isot kaupungit esiintyvät toistuvina esimerkkeinä, jolloin (juuri se peräänkuuluttamani) kokonaiskuva älykkäiden kaupunkien todelliseen kirjoon on jäänyt ottamatta (Kitchin, 2014, s. 134; Albino ym., 2015, s. 2). Maakuntien osalta tunnistetaan yhä haasteeksi älykkään erikoistumisen käsitteellistäminen, alueellinen tunnistaminen ja vaikutusten monitorointi (Karppinen ym., 2019, s. 161; Mäenpää, 2020). Älykäs kylä taas "smartperheen" tuoreena tulokkaana on vielä sisäänajossa ja jalkautettavana (mm. älykäskylä.fi). Ei siis ihme, jos kunnankin älykkäässä kehittämisessä haasteita on havaittu kumppanuuksien ja sidosryhmäverkostojen puutteesta päätöksenteon toimimattomuuteen, asenneilmaston muutoksiin ja avainhenkilöiden vaihtumiseen (Kurkela, 2016, s. 7). Käsitteellistämistä ja konseptointia piisaa toki vielä smart shrinking -ajatuksen lanseeraamisessakin (mm. schlappa \& Neill, 2013).

Älykäs kunta olisi kuitenkin hyvä ottaa asiaksi. Pienillä ja keskikokoisilla kaupungeilla totesin jo olevan perusteltu paikalliskeskus- ja tasapainottajaroolinsa kaupunki-maaseutu -jatkumossa, ja kylätkin tiedetään kekseliäisyyden ankkuripaikoiksi (Tantarimäki, 2o2oc), joten yhtälailla kunnillakin on merkityksensä kehityksen vetureina. Älykkäiden kuntien merkitys on paikoin kenties selkeämpi ja vahvempikin, sillä moni kunta on jo kokoluokaltaan suurempi kuin osa keskikokoisista kaupungeista (10 000-50 000 as.) ja etenkin pikkukaupungeista (alle 10 ooo as.). Ja jos taas kylä haluaa olla älykäs, on erikoista, etteivät muut kylät tai "kotikunta" näe samaa mahdollisuutta. Tältä se tosin vielä vähän näyttää (Tantarimäki, 2019).

Joka tapauksessa riskinä on kaiken aikaa se, että nämä "ankkuripaikat" (statuksesta riippumatta) loittonevat tai kadottavat roolinsa (ainakin hetkellisesti), kuten on jo käynyt kuntaliitosten myötä entisten kuntakeskusten kohdalla. Tämäkin on tiedostettu ja tilanteeseen puututtu niin asukkaiden aktiivisuuden kautta (mm. asukas- ja kyläyhdistysten perustaminen) kuin hankkein (mm. Kirkonkylät palvelukeskuksina/Kehittämisyhdistys Mansikka ry 2020). Sen vuoksi on väliä mitä tarkoittaa kuntienkin älykäs muutokseen sopeutuminen. 


\section{KIRJALLISUUS}

Ahonen, V.-V. \& Savolainen, S. (2020). Mitä on kuntien älykäs muutokseen sopeutuminen? [viitattu 26.5.2020] <https://valtioneuvosto.fi/artikkeli/-/asset_publisher/10623/! mita-on-kuntien-alykas-muutokseen-sopeutuminen->

Albino, V., Berardi, U. \& Dangelico, R. M. (2015). Smart Cities: Definitions, Dimensions, Performance, and Initiatives. Journal of Urban Technology, 22(1), 3-21. [viitattu 26.5.2020] <https://www.researchgate.net/ publication/311947485_Smart_Cities_Definitions_Dimensions Performance_and_Initiatives>

Borges, L. A. (2020). Geographies of labour. State of the Nordic Region. Chapter 5. Nordregio Report 2020:1. [viitattu 25.5.2020] 〈https://pub.norden.org/nord2020-001/\#18453〉

Coppola, A. (2019). Projects of becoming in a right-sizing shrinking City. Urban Geography, 40(2), 237-258. [viitattu 25.5.2020] 〈https://www.tandfonline.com/doi/abs/10.1080/02723638.2017.1421391〉

ENRD. (2018). Smart Villages. Revitalising Rural Services. EU Rural Review No 26. [viitattu 25.5.2020] <https:// enrd.ec.europa.eu/sites/enrd/files/enrd_publications/publi-enrd-rr-26-2018-en.pdf>

Hollander, J. B. \& Németh, J. (2011). The bounds of smart decline: a foundational theory for planning shrinking cities. Housing Policy Debate, 21(3), 49-367.

Jäntti, A. (2019). Kaikkia kuntia ei pitäisi ahtaa samaan muottiin. Helsingin Sanomat 5.8.2019. [viitattu 25.5.2020] 〈https://www.hs.fi/mielipide/art-2000oo6194804.html〉

Karppinen, A., Aho, S., Haukioja, T., Kaivo-oja, J. \& Vähäsantanen, S. (2019). Alueiden älykäs erikoistuminen Suomessa. Aluekehittämisen indikaattorianalyysi. Tulevaisuuden tutkimuskeskus, TUTU eJulkaisuja 4/2019. [viitattu 26.5.2020] <https://www.utu.fi/fi/julkaisut/ alueiden-alykas-erikoistuminen-suomessa-aluekehittamisen-indikaattorianalyysi>

Katajamäki, H. (2019). Aluekehittäminen ei voi perustua suuruuden logiikkaan. Lukijalta, Maaseudun Tulevaisuus 2.8.2019. [viitattu 25.5.2020] <https://www.maaseuduntulevaisuus.fi/puheenaiheet/ mielipide/artikkeli-1.480og2>

Keskipohjanmaa. (2020). Kannus mukana ainoana Keski-Pohjanmaalta Älykäs liikuntakunta -kokeilussa - Tavoitteena on lisätä omaehtoista liikuntaa digitaalisen liikuntaneuvonnan avulla. 27.1.2020. [viitattu 25.5.2020] 〈https://www.keskipohjanmaa.fi/uutinen/588320〉

Kitchin, R. (2014). Making sense of smart cities: addressing present shortcomings. Cambridge Journal of Regions, Economy and Society, 8(1), 131-136. [viitattu 26.5.2020] < https://academic.oup.com/cjres/ article/8/1/131/304592>

Kuntaliitto. (2020a). Kaupunkien ja kuntien lukumäärät ja väestötiedot. [viitattu 25.5.2020] <https://www. kuntaliitto.fi/tilastot-ja-julkaisut/kaupunkien-ja-kuntien-lukumaarat-ja-vaestotiedot>

Kuntaliitto. (2020b). Kehyskuntaverkosto. [viitattu 25.5.2020] <https://www.kuntaliitto.fi// yhdyskunnat-ja-ymparisto/kaupunkipolitiikka/kehyskuntaverkosto>

Kurkela, K., Virtanen, P., Stenvall, J. ja Tuurnas, S. (2016). Älykäs kehittämis- ja kokeilutoiminta kunnissa. Acta 263. 92 s. Kuntaliiton verkkojulkaisu.

Lindskog, H. (2004). Smart communities initiatives. Article 2004. [viitattu 25.5.2020] <https://www. researchgate.net/publication/228371789_Smart_communities_initiatives>

Lopez, I. M. \& Oliveira, P. (2017). Can a small city be considered a smart city? Procedia Computer Science 121 (2017) 617-624. [viitattu 26.5.2020] <https://www.sciencedirect.com/science/article/pii/ S1877050917322810>

Kehittämisyhdistys Mansikka ry. (2020). Kirkonkylät palvelukeskuksina. [viitattu 26.5.2020] <http://www. mansikkary.fi/fi/hankkeet/kirkonkylat-palvelukeskuksina/>

MDI. (2017). Pienten ja keskisuurten kaupunkien kukoistus. Kaupunkipolitiikan tiekartta III. [viitattu 26.5.2020] <http://www.mdi.fi/content/uploads/2017/o5/Pienten-ja-keskisuurten-kaupunkienkukoistus kaupunkipolitiikan-tiekartta-III-25042017.pdf>

Mäenpää, A. (2020). The Challenge of Public Organisations in Coordinating Smart Specialisation and a Connectivity Model as One Solution. Acta Wasaensia 438. http://urn.fi/URN:ISBN:978-952-476-898-6

Peters, D. J., Hamideh, S., Z., Kimberly, E. \& Ghandour, M. (2018). Using entrepreneurial social infrastructure to understand smart shrinkage in small towns. Journal of Rural Studies, 64, 39-49. [viitattu 26.5.2020] 〈https://www.sciencedirect.com/science/article/abs/pii/So743016718306089〉 
Schlappa, H. \& Neill, W.J.V. (2013). From crisis to choice: Re-imagining the future in shrinking cities. URBACT II. [viitattu 26.5.2020] 〈https://urbact.eu/crisis-choice-re-imagining-future-shrinking-cities >

Smart Innovation Norway. (2020). Become a smart municipality. [viitattu 26.5.2020] <https:// en.smartinnovationnorway.com/news/become-a-smart-municipality/>

Suomen kasvukäytävä. (2020). Suomen kasvukäytävä. Yhteistyöverkostomme. [viitattu 26.5.2020] <https:// suomenkasvukaytava.fi/verkostommel/>

Suomen ympäristökeskus. (2020). Hiilineutraali Suomi. [viitattu 26.5.2020] <https://hiilineutraalisuomi.fi/ fi-FI>

Sutriadi, R. (2018). Defining smart city, smart region, smart village, and technopolis as an innovative concept in Indonesia's urban and regional development themes to reach sustainability. IOP Conf. Series: Earth and Environmental Science 202 (2018). [viitattu 26.5.2020] <https://www.researchgate. net/publication/329229927_Defining_smart_city_smart_region_smart_village_and technopolis_as an innovative concept in indonesia\%27s urban and regional development themes to reach sustainability>

Syssner, J. (2020). Smart shrinking as a base of vitality. Smart schrinking - uusi alku väestöön menettäville alueille -seminaari 25.2.2020, Pikkuparlamentti, Helsinki. Alustus.

Tantarimäki, S. (2020a). Älykkäistä kylistä älykkäisiin suurkaupunkeihin - mikä on pienten ja keskikokoisten kaupunkien rooli älykkään alueen rakentajina? Terra, 132(2). Julkaistaan syksyllä 2020.

Tantarimäki, S. (202ob). Etätyö tulee taas! Työn murroksen mukanaan tuomat mahdollisuudet maaseudun kaupungeille ja kunnille. Maaseutututkimus 1/2020, 85-102. Julkaistaan keväällä 2020.

Tantarimäki, S. (2020c). Mikä ihmeen älykäs kylä? Älykkäät kylät -blogi 13.2.2020. [viitattu 26.5.2020] $\langle$ https://älykäskylä.fi/?p=63〉

Tantarimäki, S. (2019). Medianäkyvyyttä ja menestyksen aihioita. Älykkäät kylät -blogi 14.8.2019. [viitattu 26.5.2020] 〈https://älykäskylä.fi/?m=2019o8>

The Union of Municipalities of Turkey. (UMT) (2020). Smart cities and municipalities. Congress and exhibition. Viitattu 26.5.2020 <https://www.metropolis.org/agenda/ smart-cities-and-municipalities-congress-and-exhibition>

Trimis. (2019). City of Things - smart cities and municipalities. [viitattu 26.5.2020] < https://trimis.ec.europa. eu/programme/city-things-smart-cities-and-municipalities >

Valtavaara, M. (2020). Noin joka kolmas koulu voi kadota 2020-luvulla. Helsingin Sanomat 26.5.2020.

Väliharju, T. (2019). Yhteisökehittäminen haastaa älykkäät kaupungit ja kunnat. Digikilta. [viitattu 26.5.2020] <https://digikilta.fi/2019/11/11/yhteisokehittaminen-haastaa-alykkaat-kaupungit-jakunnat/>

Woien Meijer, M.\& Teräs, J. (2018). Implementing smart specialization strategies in Nordic regions. Nordregio Policy Brief 09/2019. [viitattu 26.5.2020] <https://nordregio.org/publications/] implementing-smart-specialisation-strategies-in-nordic-regions/>

Yashar, Z. E. (2016). Smart cities and smart regions: An evaluation from smart cities to smart regions. Academia. [viitattu 26.5.2020] <https://www.academia.edu/36244447/! Smart_Cities and Smart Regions An Evaluation from Smart Cities to Smart Regions > 